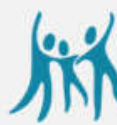

ACHNR
Asian Community Health Nursing Research

Asian Comm. Health Nurs. Res. 2020, 2(3), 33-38

\title{
Gender Dysphoria in Adolescence
}

\author{
Kiki Hardiansyah Safitri ${ }^{a^{*}}$ and Siti Mukaramah \\ Study Program of Nursing Science,Institute of Health Technology and Science \\ Wiyata Husada Samarinda, East Kalimantan Indonesia \\ akikihardiansyahs@stikeswhs.ac.id; bsitimukaramah@stikeswhs.ac.id \\ *Correspondence: kikihardiansyahs@stikeswhs.ac.id \\ Type of the Paper (Article)
}

Received: October 28, 2020; Accepted: January 10, 2021; Published: March 14, 2021

https://doi.org/10.29253/achnr.2020.23354

\begin{abstract}
Background-The end phase of the development stage of adolescents should have matured themselves in understanding gender roles in accordance with their sexual roles. Gender dysphoria occurs when adolescents experience sexual identity disorders which experience confusion over gender roles that are contrary to their sexual roles, so that they tend to like the same sex. Research ObjectivesTo identify gender dysphoria in senior high school students in Samarinda City. Methods-A descriptive study with a cross-sectional approach to 322 students in the city of Samarinda which was taken using a non-probability sampling technique: cluster random sampling. The instrument used was the Gender Dysphoria Test from psycom, through online filling. Results-Students who experienced severe-gender dysphoria were $7.8 \%$ and mild-GD around $92.2 \%$. More women $(9.3 \%)$ experienced strong gender dysphoria than men (4.2\%). There are $1.2 \%$ students who want to change their gender and $7.8 \%$ of students who do not like secondary sex characteristics currently. Conclusion-Severe-Gender dysphoria high school students have a small prevalence, GD can occur because biological or psychosocial factors can be seen from the desire and comfort of being a different gender than it should be.
\end{abstract}

Keywords: gender dysphoria; adolescence

\section{Introduction}

Adolescence is a transitional period between children and adults, when biological, intellectual, psychosocial, and economic changes are encountered (Kaltiala-Heino, et al., 2018). The psychosocial development of adolescents in a state of searching for adolescent identity fails to find their identity, so that they will experience role confusion (Kaltiala-Heino, et al., 2018). Development of identification and psychosexual is an important period held in adolescence (Kaltiala-Heino, et al., 2018). Development of Puberty in adolescent from child into young adult has seen with development of secondary sex organ. Biological sex appearance sometime inflicts discomfort situasion in several persons, which is calleGender Dysphoria (GD) (Kaltiala-Heino, et al., 2018)

Gender dysphoria which defines the DSM-5 ( $5^{\text {th }}$ edition of Diagnostic and Statiscal Manual of Mental Disorder) is person who incongruence between biological sex at birth and their desire to be other gender (American Psychiatric Association, 2013). Individual with GD look like to be treated as the other genders, tend to prefer the same sex or change themselves from male to female or female to male (Kaltiala-Heino, et al., 2018). There are two types of onsets of GD that are begun in early childhood dan after puberty. Adolescent-onset GD majority experienced early-onset GD (Littman, 2018). Centers for Disease Control 
in America has announced sex deviance in the form of gay, lesbian, bisexual, accounting for about $8 \%$ of the 1.3 million students at the senior high school level (Littman, 2018).

The problem that often occurs in adolescents who experience gender dysphoria is a sense of curiosity to seek answers that are felt without the assistance of parents and information that can be accounted for (Yarhouse, 2016). Most of the reactions of parents to children with gender dysphoria are judging and condemning them without looking for a way out or a solution, because of the lack of information and facilities for parents regarding children with gender dysphoria (Yarhouse, 2016). Adolescent with GD prefers to play with the opposite sex than the same sex, because it is often as ridicule. One of the main tasks in adolescence is to solve indentity and role confusion which is part of self concept (Yarhouse, 2016).

Clinically significant psychopathology occurs in young adults around $40-45 \%$ in adolescents who have problem gender identity. They reported that they got depression and anxiety disorder, self harm, suicidal ideation / behavior (Kaltiala-Heino et al., 2015; Zucker et al., 2015). Assumed that, GD impact is how one views of his/herself which is how he/she knows of his/herself, expect of his/herself and value of own self (Kaltiala-Heino et al., 2015; Zucker et al., 2015)

\section{Literature Review}

\section{Gender Dysphoria in Adolescents}

Psychological distress and discomfort with the gender are assigned at birth. The term was coined by Norman Fisk in 1973 explaining some of the reasons individuals seek help from professionals to explain their gender and sexual characteristics and how they perceive themselves. Since then, a wide variety of publications on transsexualism, transgenderism, and gender inconsistencies have been the center of discussion on gender-related nursing diagnoses and standards. Transsexualism, transgenderism, and gender incompatibility are different from gender dysphoria. It is common for transsexuals and transgender and gender non-conforming (TGNC) people who experience or report gender dysphoria at some point in their lifes. Many also report that they feel comfortable with their gender regardless of whether social expectations are met (Kaltiala-Heino et al., 2018).

\section{Etiology of Dysphoria Gender}

Gender dysphoria can be caused by environmental and biological factors, but experts claim there is no relative contribution of a single factor and theory about gender dysphoria. There are also many theories that the role of prenatal hormones in brain sex differentiation can cause gender dysphoria because sex differentiation takes place in the brain during the critical uterine period when testosterone is present or not and it creates certain conditions that are necessary for the brain to continue to develop as a male or female. The female brain is without testosterone, as a standard condition, while the male brain needs enough testosterone for brain development. Biologists claim that genital differences and brain sex differentiation in fetuses may explain that is match between sex and gender that exists in gender dysphoria. Empirical theoretical support for this theory comes from studies of neuroendocrine regulation in transsexuals, atypical gender behavior and gender cross-sectional identity in individuals with history of perinatal endocrine abnormalities, and neurobiological differences in the structure and function of the transsexual brain (Kaltiala-Heino et al, 2018).

Early theories emphasized the role of environmental factors rooted in the psychoanalytic and social learning traditions. Psychoanalytic theorists argue that certain characteristics of parents and the nature of the interactions with children can cause children to identify with parents of the opposite sex (Magalhães \& Magalhães, 2017). Likewise, social learning theorists point to the role of parents in gender socialization, arguing that a lack of appropriate role modeling for ineffective use of reinforcements and punishments can lead children to learn gender-incompatible behavior with the gender assigned (Magalhães \& Magalhães, 2017). A perspective emphasizing environmental factors that has gained popularity since the mid-2000s combines elements of feminist thought with multicultural psychology and Lesbian, Gay, Bisexual, Transgender (LGBT) health research to debate the role of broad societal forces in creating conditions that turn Transgenderand Gender Non-Conforming (TGNC) people into dysphoric (Magalhães \& Magalhães, 2017Confusion and distress about one's gender is seen as a natural consequence of living in a society that stigmatizes normal gender variations and marginalizes TGNC individuals (Magalhães \& Magalhães, 2017). 


\section{Symptoms of Gender Dysphoria in Adolescents}

Signs of gender dysphoria are seen in childhood and can carry over into adolescence. As adolescents feel more pronounced gender dysphoria, you mayfeel: (1) without a doubt that your gender identity conflicts with your biological gender, (2) feeling comfortable only when in the gender role of your preferred gender identity, (3) a strong desire to conceal or eliminate physical signs of your sex, such as breasts, body hair or muscle definition, (4) a strong dislike for and a strong desire to change or remove the genitals of biological sex, (5) they may avoid bathing or changing clothes or having sex to avoid or see their genitals (Magalhães \& Magalhães, 2017). Without the right help or support, people with gender dysphoria will continue to suppress feelings and try to live life as their biological sex, but in the end, they will not be able to continue with it. As a result, many transgender women or people with gender dysphoria experience depression, self-harm, or attempt suicide (Magalhães \& Magalhães, 2017).

\section{Methodology}

The study design is a descriptive study with a cross sectional approach. The population in this study is senior high schools in Samarinda City. Samarinda City has 10 districts, each district is represented by one senior high school (30-40 students). Non-probability sampling (clusterrandom sampling) obtained a sample of 322 students. The instrument used is the Gender Dysphoria Test. The measurements are carried out using https://www.psycom.net/adult-gender-dysphoria-test/.

\section{4. $\quad$ Result}

Table 1. Gender dysphoria test.

\begin{tabular}{|c|c|c|c|c|c|c|c|}
\hline \multirow{2}{*}{ No } & \multirow{2}{*}{ Variabel } & \multicolumn{2}{|c|}{ Yes } & \multicolumn{2}{|c|}{ No } & \multicolumn{2}{|c|}{ Sometime } \\
\hline & & $\mathbf{f}$ & $\%$ & f & $\%$ & f & $\%$ \\
\hline 1 & Gender identity is at odds with your biological sex & 6 & 1.8 & 301 & 93.5 & 14 & 4.3 \\
\hline 2 & $\begin{array}{l}\text { Dislike your genitals and secondary sex characteristics } \\
\text { (e.g., facial hair or breasts) of your assigned gender }\end{array}$ & 25 & 7.8 & 279 & 86.6 & 18 & 5.6 \\
\hline 3 & $\begin{array}{l}\text { Feeling happier if you had the primary or secondary } \\
\text { sex characteristics of the opposite gender? }\end{array}$ & 20 & 6.2 & 272 & 84.5 & 30 & 9.3 \\
\hline 4 & $\begin{array}{l}\text { Considered procedures to physically alter your sexual } \\
\text { characteristics }\end{array}$ & 4 & 1.2 & 316 & 98.1 & 2 & 0.6 \\
\hline 5 & $\begin{array}{l}\text { A wish that the people in your life would treat you the } \\
\text { same way they treat males (if your assigned gender is } \\
\text { female) or females (if your assigned gender is male) }\end{array}$ & 14 & 4.3 & 278 & 86.3 & 30 & 9.3 \\
\hline 6 & $\begin{array}{l}\text { Have feelings with the same sex (for example, men but } \\
\text { attracted to men or women but attracted to women) }\end{array}$ & 4 & 1.2 & 308 & 95.7 & 10 & 3.1 \\
\hline 7 & $\begin{array}{l}\text { Experiencing distress or impairment in social, } \\
\text { occupational, or other important areas of functioning }\end{array}$ & 20 & 6.2 & 252 & 78.3 & 50 & 15.5 \\
\hline
\end{tabular}

Table 1 shows the frequency distribution of Adolecence whose gender identity is odd with biological gender is around $6.2 \%$ (either they feel yes or just sometimes feel sometime odd). Pervalence adolescence that dislike your genitals and secondary sex characteristics (e.g., facial hair or breasts) of your assigned gender is $13.4 \%$ (either they feel yes or just sometimes feel dislike). Pervalence adolescence who is happier had primary sor secondary sex characteristic of opposite gender, like have long hair in man or short hair in woman so their look like opposite gender is 15.5\% (either they feel yes or just sometimes feel happy). Pervalance adolescence who considered procedures to physically alter your sexual characteristics $1.8 \%$ either they feel yes or just sometimes want to alter their sex characteristic). Prevalance adolescence who wish other people treat them same way as opposite gender (as male like to be treated as woman or vice versa) is 13.6\% (either they feel yes or just sometimes have a wish). Prevalance adolescence who have feelings with the same sex as men but attracted to men or women but attracted to women is $4.3 \%$ (either they feel yes or just sometimes they have feeling). Prevalance adolescence who are experiencing distress or impairment in social, occupational, or other 
important areas of functioning about themselves $21.7 \%$ (either they feel yes or just sometimes they have feeling)

Table 2. Distribution of gender dysphoria.

\begin{tabular}{llcccccc}
\hline & & \multicolumn{6}{c}{ Sex } \\
\cline { 3 - 8 } No Gender Dysphoria & \multicolumn{2}{c}{ Man } & \multicolumn{2}{c}{ Woman } & \multicolumn{2}{c}{ Total } \\
\cline { 3 - 8 } & & f & \% & f & \% & f & \% \\
\hline 1 & Mild-Gender Dysphoria & 92 & 95.8 & 205 & 90.7 & 297 & 92.2 \\
2 & Severe-Gender Dysphoria & 4 & 4.2 & 21 & 9.3 & 25 & 7.7 \\
& Total & 96 & 29.8 & 226 & 70.3 & 322 & 100 \\
\hline
\end{tabular}

Gender Dysphoria test in https://www.psycom.net/adult-gender-dysphoria-test gets $92.2 \%$ with Mild-GD and 7.7\% with Severe-GD 9.3\%. Adolescences with severe-GD are 84\% woman and 16\% man (Table 2). Distribution of severe-GD finds that $100 \%$ adolescenes consider altering their sexual. SevereDG who are happier had primary or secondary characteristic of opposite gender around $56 \%, 64 \%$ of them wish people treat as same way with opposite their biological sex (Table 3).

Table 3. Item gender dysphoria test in adolescence with severe GD.

\begin{tabular}{|c|c|c|c|c|c|c|c|}
\hline \multirow{2}{*}{ No } & \multirow{2}{*}{ Variabel } & \multicolumn{2}{|c|}{ Yes } & \multicolumn{2}{|c|}{ No } & \multicolumn{2}{|c|}{ Occasionally } \\
\hline & & f & $\%$ & $\mathrm{f}$ & $\%$ & $\mathrm{f}$ & $\%$ \\
\hline 1 & Gender identity is at odds with your biological sex & 2 & 8 & 16 & 64 & 7 & 28 \\
\hline 2 & $\begin{array}{l}\text { Dislike your genitals and secondary sex } \\
\text { characteristics (e.g., facial hair or breasts) of your } \\
\text { assigned gender }\end{array}$ & 8 & 32 & 11 & 44 & 6 & 24 \\
\hline 3 & $\begin{array}{l}\text { Feeling happier if you had the primary or secondary } \\
\text { sex characteristics of the opposite gender? }\end{array}$ & 8 & 32 & 6 & 24 & 11 & 44 \\
\hline 4 & $\begin{array}{l}\text { Considered procedures to physically alter your sexual } \\
\text { characteristics }\end{array}$ & 4 & 16 & 0 & 0 & 21 & 84 \\
\hline 5 & $\begin{array}{l}\text { A wish that the people in your life would treat you the } \\
\text { same way they treat males (if your assigned gender is } \\
\text { female) or females (if your assigned gender is male) }\end{array}$ & 10 & 40 & 9 & 36 & 6 & 24 \\
\hline 6 & $\begin{array}{l}\text { Have feelings with the same sex (for example, men } \\
\text { but attracted to men or women but attracted to } \\
\text { women }\end{array}$ & 2 & 8 & 17 & 68 & 6 & 24 \\
\hline 7 & $\begin{array}{l}\text { Experiencing distress or impairment in social, } \\
\text { occupational, or other important areas of functioning }\end{array}$ & 7 & 28.5 & 16 & 64 & 2 & 8 \\
\hline
\end{tabular}

\section{Discussion}

Biologically, sex differences both of body, brain and behavior influence by multiple factor, such as sex-chromosomal, hormonal, genetc and epigenetic contribution (Arnold, 2015; Nugent et al., 2015). Sensitivity of brain release unity effect of sex hormones which appears high level at prenatal/perinatal stages of development and decline gradually in adulthood. Hormonal secretion gives three sensitive periods, (1) pre/perinatal, (2) pubertal, and (3) the first of pregnancy (in female) (Schulz et al., 2009). Behavior effect from strong prenatal androgenization, this evidence is got from studies of individual with somatic intersex with various levels of androgen exposure (Somatic intersex: condition that affection or characteristic of chromosomal sex inconsistent with genital sex or gonad sex is not classifiable as either male or female) (Byne, 2018).

Most of genital differentiation period precede the sexual differentiation of the brain. In case of GD without somatic intersex condition could look like a person with brain-intersex condition (Byne et al., 2012). The gender dysphoria test assesses a person into two categories as mild and severe, causing every human being has the possibility of experiencing GD. Early hormonal exposure on the development 
gender in infant or pranatal, regardless of genetic constitution, has increased GD probability when was born as baby girl (Byne et al., 2012).

Psychosocial and social are major additional factor influencing gender in human being such as verbal labeling (boy and girl) and nonverbal gender (specific outfit, haircut between boys and girls) from their parents, family and social (Blakemore et al., 2008). Since childhood, gender behavior in adolescence was shaped by gender-role expectation from people around them (Blakemore et al., 2008). The development process of children is related by learning or imitating from selective-gender observation, gender stereotypes, self-concept, and socialization (Blakemore et al., 2008). Effect of psychosocial is not determinative because biology factor tells that GD happens because of chromosom sex and hormone interaction that appears in people with somatic intersex (Blakemore et al., 2008).

The development tasks of adolescence are involved accepting their body, adopting masculine or feminime social role, having independent emotional from parents, having close relantionship with peer friends either same or opposite gender, preparing themselves for being a worker, preparing themselves for marriage and having nuclear family life, building a personal value, and achieving responsibility role from social (Blakemore et al., 2008). There are two onsets of GD, early childhood, and late-onset GD that symptom begins in after puberty. Majority of Late-onset GD (adolescence onset) is experienced early onset-GD that persisted or worsened with puberty (Littman, 2018). Persisten GD appears with consideration to alter their charactheristic look like, with consume extra hormone of opposite biological sex (Littman, 2018).

Peer relantionships are critical for psychological well being and shaping development of identity consolidation in adolescence. Adolescence with GD got bullying from same sex peer relantionship so that they comfort association with opposite sex, this social life makes them treated not as their biological gender. This research finds that $13.6 \%$ from all adolescents is happy treated as opposite their biological sex, and prevalance among adolescent with severe-GD around 64\% happy treatead as opposite their biological sex. Bullying in adolescence with GD makes them distress and feel impaired in social, in this research finding about 36\% adolescence with severe GD who experience distress and impairment in social. Social and peer contangion as cluster outbreak of GD. Peer contangion occurring people from friends or peer group who existing, they influence others from their daily life in social media/internet as preceding a child's announcement of transgender indetity, possibility raise social and peer contangion (Kaltiala-Heino et.al., 2018).

GD in Indonesia is taboo and society does not accept it because it is against the religion adhered in Indonesia (Saroh \& Relawati, 2017). Some of parents do not realize their child is GD and consider they are normal or common as adolescent due to puberty (Saroh \& Relawati, 2017). But after signs and symptoms of GD persisted, the parents have begun to deny their existence. Another research in aboard finds different, there are cases from minority family background that is also from LGBT community, so that their children also get GD, a not-terrible situation(Saroh \& Relawati, 2017). Gender-minority offspring reported particular positive aspect of being a parent in GD situation such as human being had a personal growth that could not be equated with others; unconditional love to their children and family whatever they look like; activism GD as solidarity to other families that find the same situation by whicch they do not interfere with social relantionship (Saroh \& Relawati, 2017).

\section{Conclusion}

Severe-Gender dysphoria high school students have a small prevalence, GD can occur because biological or psychosocial factors can be seen from the desire and comfort of being a different gender than it should be.

\section{Acknowledgement}

Thanks for Education Ministry for funding this research in novice lecturer research. Thanks for Institute of Health Science Wiyata Husada for support in all process in this research, headmasters and teachers at senior high schools in Samarinda City, East Kalimantan, Indonesia as field of research. Last but not least, Capitol Toefl Center for doing proofreading this article. 


\section{References}

American Psychiatric Association. (2013). Diagnostic and Statistical Manual of Mental Disorders. 5th ed. Washington.DC: American Psychiatric Press

Arnold, A.P. (2017) general theory of sexual differentiation. J Neurosci Res. 95: 291-300.

Blakemore, J.E., Berenbaum, S., \& Liben, L.S. (2008) Gender Development. New York: Psychology Press

Byne, W., Bradley, S,J., Coleman, E., et al. (2012) Report of the American Psychiatric Association Task Force on Treatment of Gender Identity Disorder. Arch Sex Behav. 41:759-796.

Byne, et al. (2018) Gender Dysphoria in Adults: An Overview and Primer for Psychiatrists. Transgender Health, 3.1 http://online.liebertpub.com/doi/10.1089/trgh.2017.0053

Kaltiala-Heino, R., Sumia, M., Tyolajarvi, M., \& Lindberg, N. (2015). Two years of gender identity service for minors: overrepresentation of natal girls with severe problems in adolescent development. Child Adolesc Psychiatry Ment Health 9(9). DOI: 10.1186/s13034-015-0042-y

Kaltiala-Heino, Riittakerttu., Bergman, Hannah., Työläjärvi, Marja \& Frisé, Louise. (2018). Gender dysphoria in adolescence: current perspectives. Adolescent Health, Medicine and Therapeutics: 9 (31-41). doi: 10.2147/AHMT.S135432

Littman, L., (2018) Rapid-onset gender dysphoria in adolescents and young adults: A study of parental reports. PLoS ONE 13(8): e0202330. https://doi.org/10.1371/journal.pone.0202330

Magalhães, Cristina L. \& Magalhães Ellen S. (2017). Gender Dysphoria. The SAGE Encyclopedia of Psychology and Gender (p:651-654). Thousand Oaks: SAGE Publications, Inc. DOI: http://dx.doi.org/10.4135/9781483384269

Nugent, B,M., Wright, C,L., Shetty, A,C., et al. (2015). Brain feminization requires ac- tive repression of masculinization via DNA methylation. Nat Neurosci. 18:690-697.

Saroh, Y. \& Relawati, M. (2017). Indonesia youth perspective toward LGBT. Humanus 16(1): 71-82. http://dx.doi.org/10.24036/jh.v16i1.7323

Schulz, K,M., Molenda-Figueira, H. A., \& Sisk, C.L. (2009) Back to the future: the organizational-activational hypothesis adapted to puberty and adoles- cence. HormBehav 55:597-604.

Yarhouse, M. A. (2016). Understanding Gender Dysphoria: Navigating Transgender Issues in A Changing Culture. Perspectives on Science and Christian Faith, vol. 68(4). p274+

Zucker, K.J., Bradley, S.J., Owen-Anderson, A., et al. (2012). Demographics, behavior problems, and psychosexual characteristics of adolescents with gender identity disorder or transvestic fetishism. J Sex Marital Ther (38)151-189.DOI: doi: 10.1080/0092623X.2011.611219 